\title{
Educação inclusiva: análise e intervenção em uma sala de recursos ${ }^{1}$
}

\author{
Marileide Antunes de Oliveira ${ }^{2}$ \\ Universidade Federal de São Carlos, São Carlos-SP, Brasil \\ Lúcia Pereira Leite \\ Universidade Estadual Paulista, Bauru-SP, Brasil
}

\begin{abstract}
Resumo: Este artigo se fundamenta no Paradigma de Suportes que norteia a educação inclusiva, a qual prevê ajustes educacionais para que todos os alunos participem da escola comum. O estudo teve por objetivo analisar o funcionamento de uma sala de recursos e descrever a intervenção realizada com uma professora especialista. A coleta de dados consistiu das fases: (a) descrição da sala de recursos; (b) análise do plano de ensino da professora; (c) aplicação de entrevistas e discussões sobre teoria e prática na educação inclusiva com a professora especialista; (d) preenchimento do documento de adaptações curriculares individuais para os alunos. A análise contou com os procedimentos: caracterização da realidade investigada, análise das entrevistas e análise comparativa das adaptações curriculares. Como resultados, o estudo aponta a existência de divergências entre políticas educacionais e realidade escolar investigada. A intervenção permitiu que a professora refletisse sobre a sua atuação com base em novos procedimentos de ensino.
\end{abstract}

Palavras-chave: educação inclusiva, psicologia educacional, objetivos educacionais, currículo, educação especial.

\section{Inclusive education: analysis and intervention in a special classroom}

\begin{abstract}
This paper is based on the Support Paradigm, which establishes the principles to the inclusive education, which indicates educational adjustments participating in the regular school to all students. This study aimed to analyze a special classroom working arrangements and to describe an intervention implemented having a special classroom teacher as participant. Data collection comprised the following phases: (a) special classroom description; (b) analysis of the teacher's teaching plan; (c) application of survey and discussion comprising theory and practice on inclusive education; (d) curricular adaptation fulfilling. Data analysis comprised: special classroom characterization, survey analysis, comparative analysis of curricular adaptation. As results, the study shows divergences between public educational policies and school reality. The intervention provided the teacher with a reflection about her on-work performance based on new teaching procedures.
\end{abstract}

Keywords: inclusive education, educational psychology, educational objectives, curriculum, special education.

\section{Educación inclusiva: un análisis y intervención en un aula de recursos}

Resumen: Este artículo se fundamenta en el Paradigma de Soportes que nortea la educación inclusiva, que preve unos ajustes educacionales para los alumnos participan en la escuela común. Objectivó analizar el funcionamiento de un aula de recursos y describir la intervención realizada con una profesora especialista. La recolección de datos consistió de las fases: (a) descripción del aula de recursos; (b) análisis del plan de estudios de la profesora; (c) aplicación de entrevistas y discusión sobre teoría y práctica y enseñanza inclusiva; d) cumplimiento de adaptaciones curriculares. Para el análisis de los datos, fueron adoptados los procedimientos: la caracterización de la realidad investigada, el análisis de las entrevistas y comparación de las adaptaciones curriculares. Como resultados, el estudio apunta la existencia de divergencias entre políticas educacionales y la realidad escolar. La intervención permitió que la profesora reflexionara sobre su actuación bajo nuevos procedimientos de enseñanza.

Palabras clave: educación inclusiva, psicología educacional, objetivos educacionales, curriculum, educación especial.

A proposta de transformações amplas e profundas nos sistemas educacionais para a construção de um novo modelo de ensino teve como marco a assembleia realizada na

\footnotetext{
${ }^{1}$ Este texto foi revisado seguindo o Acordo Ortográfico da Língua Portuguesa (1990), em vigor a partir de $1^{\circ}$ de janeiro de 2009. Artigo decorrente da Dissertação de Mestrado da primeira autora defendida no Programa de Pós-graduação em Psicologia do Desenvolvimento e Aprendizagem da Universidade Estadual Paulista, campus Bauru, em março de 2008, e orientada pela segunda autora.

${ }^{2}$ Endereço para correspondência:

Marileide Antunes de Oliveira. Rua Iwagiro Toyama, 70, apto. 3, Bloco 1. CEP 13.564-380. São Carlos-SP, Brasil. E-mail:

marileide.antunes@yahoo.com.br
}

Espanha, em junho de 1994, com representantes de 88 governos e 25 organizações internacionais, a partir da qual se passou a advogar uma "Educação para Todos" (Declaração de Salamanca, 1994).

Diante disso, tornou-se diretiva mundial a reorganização do sistema educacional para garantir a todo e qualquer aluno o acesso, o ingresso e a permanência nas mais diversas modalidades de escolarização existentes nas instituições de ensino (Claser, 2001). Assim como em diversos países, atualmente, diretrizes têm sido elaboradas no contexto brasileiro para respaldar a implementação da inclusão educacional.

Atualmente, políticas públicas têm se voltado para a promulgação de leis e resoluções que viabilizem a educação inclusiva, dentre as quais se destacam as Diretrizes Nacionais 
para a Educação Especial na Educação Básica (Ministério da Educação, 2001). Nesse documento, são explicitadas mudanças substanciais em componentes do processo escolar, tais como: currículo, organização da escola, metodologia de ensino, uso de estratégias diferenciadas, pressupostos teórico-filosóficos, atividades extracurriculares e atitudes educacionais, para reiterar o compromisso de garantir a todos os alunos o ensino em espaço comum (Oliveira, 2006).

Ao propor um novo enfoque para a Educação Especial, as Diretrizes Nacionais indicam a ampliação dos serviços ofertados, sugerindo que, no contexto da inclusão educacional, essa área deve assumir um novo papel. Em vez de se destinar apenas ao atendimento de alunos com deficiência, altas habilidades, síndromes e quadros psicológicos, o documento assume que a Educação Especial deve compor um conjunto de serviços e apoios com caráter dinâmico, temporário e relativo para o atendimento dos alunos com necessidades educacionais especiais (NEEs), de acordo com Oliveira e Leite (2002).

Da mesma forma, a adoção do conceito de NEEs nas Diretrizes Nacionais representa também um avanço, uma vez que permite caracterizar a população a se beneficiar dos apoios da Educação Especial. De acordo com esse documento, os alunos com necessidades educacionais especiais são aqueles que, durante o processo educacional, apresentam:

(1) dificuldades acentuadas de aprendizagens ou limitações no processo de desenvolvimento que dificultem o acompanhamento das atividades curriculares, compreendidas em dois grupos: (a) aquelas não vinculadas a uma causa orgânica específica; (b) aquelas relacionadas a condições, disfunções, limitações ou deficiências; (2) dificuldades de comunicação e sinalização diferenciadas dos demais alunos, demandando a utilização de linguagens e códigos aplicáveis; (3) altas habilidades/superdotação, grande facilidade de aprendizagem que os leve a dominar rapidamente conceitos, procedimentos e atitudes (Ministério da Educação, 2001, p. 17).

A expressão necessidades educacionais especiais surge, segundo o mesmo documento, para possibilitar uma análise mais ampla das respostas educacionais a segmentos populacionais diversos. Como destacado por Oliveira (2006), o atual enfoque dado pelas Diretrizes Nacionais prevê que as dificuldades escolares, mesmo relacionadas a causas orgânicas, devem ser identificadas "durante o processo educacional, e não fora dele" (p. 261, grifos da autora).

Fazendo um contraponto com o processo de ensino e de aprendizagem, tem-se um novo modo de atuação educacional, contrário a um modelo de ensino homogêneo, constituído de atuações pedagógicas muito semelhantes, as quais desconsideram as particularidades no aprender dos diversos alunos que compõem a classe. Por outro lado, ao se pensar em um ensino heterogêneo, preconizam-se as diferenças pessoais como parte das relações de ensino e aprendizagem e, sendo assim, é papel do sistema educacional promover as condições para que todo e qualquer aluno aprenda, inclusive os com deficiência (Leite, 2004).

No contexto de inclusão educacional, a sala de recursos ganha papel fundamental na viabilização do acesso da parcela de alunos com NEEs ao currículo comum. De acordo com as recomendações legais, no caso, as Resoluções SE No. 8 (2006) e SE No. 11 (2008), a sala de recursos compõe um dos suportes existentes na Educação Especial e oferece serviço de natureza pedagógica, a fim de complementar ou suplementar o atendimento educacional fornecido na sala comum.

Para garantir a participação dos alunos com NEEs no processo educacional, há a indicação de que o professor da sala de recursos, que possui formação em educação especial, auxilie a equipe escolar na implementação de um ensino responsivo à parcela de alunos com NEEs, por meio de ajustes nos conteúdos e objetivos curriculares, recursos e estratégias metodológicas, dentre outros (Resolução SE No. 8, 2006).

Dentre as maneiras pelas quais o professor pode realizar tais modificações, estão as adaptações curriculares. Como define Correia (1999), as adaptações curriculares são alterações ou transformações que os professores e a escola fazem nas propostas curriculares, a fim de promover as condições necessárias ao ensino na diversidade. Elas podem ocorrer tanto nos elementos básicos do currículo quanto nos que tornem possível o acesso a este.

As adaptações curriculares têm como pressuposto a compreensão dos diferentes ritmos e formas de aprender. Logo se constituem como uma ferramenta importante para pensar e propor um ensino responsivo aos alunos que delas necessitam para acessar a proposta educacional ofertada.

Assim, este estudo teve como objetivo caracterizar o funcionamento de uma sala de recursos e realizar intervenção junto a uma educadora especialista para auxiliá-la na implementação de ações educacionais inclusivas, entre elas, a adoção e preenchimento de um documento de adaptações curriculares, para favorecer que os alunos dessa sala pudessem acessar o currículo comum - como qualquer aluno da escola.

Buscou-se subsidiar este trabalho nos princípios da psicologia histórico-cultural na tentativa de compreender o fenômeno da inclusão educacional como processo pelo qual são dadas as condições para o desenvolvimento humano. À luz desse referencial, assume-se o tornar-se humano como tarefa coletiva vinculada ao processo de apropriação da cultura, e a educação como sua condição determinante (Pino, 2005). Numa alusão aos preceitos educacionais, tem-se a figura do professor que desempenha papel fundamental nesse processo, ao atuar como mediador na identificação dos elementos culturais que devem ser apropriados pelo aluno, para que este desenvolva habilidades acadêmicas, criadas ao longo da história e tão necessárias para o seu desenvolvimento humano. 


\section{Método}

\section{Participantes e local}

A seleção da escola onde o estudo foi realizado se deu por contato anterior com a direção e coordenação pedagógica, em virtude de pesquisas realizadas anteriormente. Nesses estudos, foi levantada a necessidade de se prover suporte metodológico à professora especialista, alocada na sala de recursos, que relatava dificuldade em operacionalizar estratégias didáticas para atender os alunos matriculados no serviço.

Com isso, optou-se por desenvolver a pesquisa nessa escola que pertence à rede estadual de ensino fundamental de um município do oeste paulista, tendo, como participante, a referida professora especialista, atuante em sala de recursos na área de Deficiência Mental. Na época de desenvolvimento da pesquisa, a sala oferecia atendimento especializado a 27 alunos, 13 matriculados regularmente e 14 em situação irregular.

\section{Instrumentos}

Para a coleta de dados, foram lidos e analisados documentos oficiais relativos aos planos de ensino e às fichas pedagógicas dos alunos matriculados na sala de recursos. Além disso, três roteiros, de observação, de análise da prática pedagógica e de entrevista, foram elaborados e aplicados durante o estudo. No período de intervenção, quatro textos de apoio foram utilizados para a discussão sobre práticas educacionais inclusivas e, por fim, foi realizado o preenchimento do Documento Individual de Adaptações Curriculares (Poker \& Oliveira, 2006).

Os roteiros tiveram como finalidade auxiliar na observação das aulas, na análise da proposta pedagógica, sendo construídos à luz de documentos legais - Resolução SE No. 8 (2006) e Diretrizes Nacionais (Ministério da Educação, 2001) - ou seja, após leitura foram selecionados e extraídos aspectos pedagógicos considerados fundamentais para a implementação da educação inclusiva.

O roteiro de observação foi elaborado para conduzir anotações de dados de campo, durante a caracterização do funcionamento da sala de recursos, e era composto dos itens: (a) horário de atendimento; (b) número de alunos; (c) condições físicas da sala; (d) existência e utilização de equipamentos de apoio pedagógico; (e) características gerais da população atendida, da atuação pedagógica e das atividades realizadas.

O roteiro para análise da proposta pedagógica foi elaborado com o objetivo de mapear o atendimento oferecido na sala de recursos analisando: (a) existência de plano de ensino na sala de recursos; (b) relação deste com o plano da sala comum; (c) previsão de adaptações de conteúdo, estratégias, avaliação e/ou recursos em função das necessidades do aluno; (d) previsão de metas para o aluno no ensino comum; (e) colaboração com o professor da sala comum.

O roteiro norteador de entrevista foi construído, a fim de averiguar a compreensão da professora acerca do atendimento oferecido na sala de recursos, bem como identificar possíveis mudanças em seu relato, após o período de intervenção. O roteiro foi composto de 18 questões abertas envolvendo alguns aspectos que podem ser sintetizados em: (a) conceitos de sala de recursos, de alunos com necessidades educacionais especiais e de educação inclusiva; (b) rotina de atendimento; (c) planejamento pedagógico quanto a objetivos, conteúdos e metas para o aluno no ensino comum; (d) características dos alunos atendidos; (e) trabalho com o professor da sala comum e dificuldades na atuação pedagógica; (f) participação dos pais.

Já o Documento Individual de Adaptações Curriculares (ACI) é uma adaptação do trabalho de Landívar e Hernández (1995) e se refere a uma proposta de ajustes no currículo a serem realizados em caráter individual, em resposta às necessidades educacionais de alunos que não conseguem acessar o currículo proposto pela escola. Este documento é composto de oito itens: (a) dados de identificação da escola; (b) dados pessoais do aluno; (c) histórico da aprendizagem do aluno e apoio recebido; (d) caracterização pessoal/desenvolvimento do aluno; (e) estilo de aprendizagem e motivação para aprender; (f) proposta curricular adaptada/área de Língua Portuguesa; (g) proposta curricular adaptada/área de Matemática; (h) modalidades de serviço frequentadas pelo aluno.

Por fim, os textos de apoio foram organizados, a partir da seleção de trechos e/ou citações indiretas retiradas de Stainback e Stainback (1999), a respeito de temáticas correlacionadas com a inclusão educacional, mais especificamente: (a) envolvimento da família na educação do aluno com NEEs; (b) educação especial no contexto do ensino inclusivo; (c) necessidades educacionais especiais; (d) adaptações curriculares.

\section{Procedimento}

\section{Coleta de dados}

A coleta de dados ocorreu durante o período de agosto de 2006 a junho de 2007, com intervalo entre dezembro e março, em função das férias escolares. Inicialmente, foi realizado um levantamento das principais características da realidade investigada neste estudo, a partir de observações na sala de recursos, que duravam uma hora, ocorrendo três vezes por semana, ao longo de um mês, com o auxílio do roteiro de observação. As anotações de campo foram complementadas com informações obtidas por meio de leitura das fichas de alunos e dos documentos fornecidos pela professora a respeito de sua proposta pedagógica.

Em seguida, conduziu-se uma análise comparativa entre o plano de ensino ou proposta pedagógica utilizada pela professora e o correspondente ao ensino comum. Para tanto, foram realizadas visitas previamente agendadas à escola, no 
mês de setembro de 2006. Durante a análise, os planos de ensino da sala comum e da sala de recursos eram comparados, tendo como base o roteiro de análise da proposta pedagógica que tinha como objetivo mapear o atendimento pedagógico ofertado na sala de recursos.

Recorreu-se, então, à aplicação do roteiro norteador de entrevista em momentos distintos, um anterior à intervenção realizada e outro logo na sequência, para averiguar a compreensão da professora especialista acerca do atendimento realizado na sala de recursos, bem como para identificar possíveis mudanças em seu relato. As entrevistas foram conduzidas na sala de recursos, seu conteúdo foi transcrito na íntegra para posterior análise.

A partir disso, foram realizados quatro encontros reflexivos, momentos semanais em que era discutida, pela díade - pesquisadora e professora, a prática pedagógica da sala de recursos, com o auxílio dos textos de apoio, ou seja, a pesquisadora solicitava à professora relatar a sua prática pedagógica, fazendo algumas inferências com base nas suas observações de campo. Nesses encontros objetivou-se, também, discutir sobre os procedimentos a serem adotados para o preenchimento e implementação do Documento Individual de Adaptações Curriculares (ACI) (Poker \& Oliveira, 2006).

Inicialmente, propôs-se que os documentos seriam preenchidos pela professora especialista e aplicados na sala regular, porém, algumas dificuldades foram encontradas: dificuldade da docente em compreender e responder às informações solicitadas no documento e resistência em estabelecer um trabalho conjunto com os professores de ensino comum. Assim, optou-se por realizar o preenchimento dos documentos de adaptações curriculares para o contexto específico da sala de recursos, sendo a professora especialista a responsável pela implementação das adaptações, já que ela não dispunha de um plano individualizado para os alunos atendidos nesse serviço, como constatado durante a análise comparativa entre o plano de ensino utilizado pela professora e o correspondente no ensino comum.

O preenchimento dos itens presentes nos documentos de adaptações curriculares foi, então, realizado conjuntamente - pesquisadora e professora, a partir da discussão a respeito de quais mudanças poderiam ser realizadas, tomando como base a realidade educacional de cada aluno em questão. No total, foram preenchidos 13 documentos individuais de adaptações curriculares para alunos matriculados na sala de recursos, sendo um em abril, cinco em maio e sete em junho de 2007. A implementação das adaptações propostas foi acompanhada por meio de visitas previamente estabelecidas à sala de recursos, porém, esta se deu apenas parcialmente, pois: (a) em função de os alunos frequentarem a sala em períodos diferentes dos preestabelecidos, não foi possível observar se todas as atividades realizadas pela professora estavam contempladas no documento; (b) em função do término previsto para a coleta de dados, foi possível acompanhar somente o início da implementação das adaptações. No entanto, foi acordado que a professora se responsabilizaria pelo desenvolvimento das adaptações curriculares previstas nos documentos, com margem mínima de um semestre letivo.

\section{Análise dos dados}

Os dados obtidos foram agrupados e organizados em três níveis. Primeiramente, procurou-se retratar a realidade investigada, a fim de averiguar se as condições encontradas na sala de recursos em que foi conduzida a pesquisa estavam de acordo com o disposto nas Diretrizes Nacionais para a Educação Especial na Educação Básica (Ministério da Educação, 2001) e na Resolução SE No. 8 (2006).

Após, buscou-se fazer uma análise entre o que a professora compreendia sobre o funcionamento da sala de recursos em dois momentos, pré e pós-implementação dos documentos de adaptações curriculares, em relação ao que é estabelecido pela respectiva legislação.

Por fim, procurou-se averiguar em que medida a proposta de intervenção pôde auxiliar a professora no atendimento realizado na sala de recursos, por meio da análise do preenchimento dos itens dispostos no documento de adaptações curriculares, de modo a identificar como ela compreendia tais itens.

Para a caracterização da realidade investigada, a saber, o funcionamento da sala de recursos e as suas proposições pedagógicas, foi realizada uma análise comparativa entre os dados obtidos com a aplicação dos roteiros de observação e de análise da proposta pedagógica em relação ao estabelecido nas normas legais dispostas na Resolução SE No. 8 (2006) e nas Diretrizes Nacionais (Ministério da Educação, 2001), averiguando a existência de possíveis discrepâncias entre os dados obtidos e o recomendado legalmente, no que se refere à implementação da educação inclusiva.

Tal procedimento foi igualmente utilizado para a análise das entrevistas realizadas com a professora. A partir da leitura do conteúdo das entrevistas, buscou-se averiguar os aspectos concordantes e/ou dissonantes em seu relato em comparação ao estabelecido pelos documentos oficiais mencionados.

Para a análise do preenchimento dos itens dos documentos de adaptações curriculares, foi realizada uma análise comparativa intragrupal, ou seja, foi comparado o disposto em cada um dos itens dos documentos dos 13 alunos da sala de recursos, para identificar se a professora havia realmente realizado uma proposta de intervenção pedagógica individual, conforme determinado no documento Individual de Adaptações Curriculares (Poker \& Oliveira, 2006). Tal procedimento teve como referencial a análise dos dados preenchidos no que se refere aos itens: (a) histórico da aprendizagem do aluno e apoio recebido; (b) caracterização pessoal do desenvolvimento do aluno; (c) estilo de aprendizagem e motivação para aprender; (d) proposta curricular adaptada - área de Língua Portuguesa - referentes curriculares, análise do desempenho do aluno - o que faz 
com e sem ajuda, conteúdos curriculares a serem ensinados, estratégias metodológicas a serem adotadas, avaliação dos objetivos da proposta.

Para a análise comparativa intragrupal, os documentos de adaptações individuais foram divididos em três grupos. O Grupo 1 (G1) corresponde a uma adaptação realizada no mês de março de 2007. Já o Grupo 2 (G2) se refere ao conjunto de adaptações que foram implementadas para cinco alunos entre os meses de abril e maio de 2007 e, por fim, o Grupo 3 (G3) contempla os sete outros documentos que foram preenchidos no final da intervenção.

\section{Considerações éticas}

A presente pesquisa foi aprovada pelo Comitê de Ética em Pesquisa da Faculdade de Ciências da Universidade Estadual Paulista (Protocolo $n^{\circ}$ 2513/46/01/07). A participação da professora foi oficializada com a assinatura do Termo de Consentimento Livre e Esclarecido.

\section{Resultados e Discussão}

A apresentação dos resultados e discussão ocorrerá em três níveis - análise da realidade investigada, análise das entrevistas e análise da proposta de intervenção -, tendo como subsídio os conceitos da psicologia histórico-cultural (Vygotsky, 2001).

\section{Análise da realidade investigada}

Quanto ao número de alunos e horário de atendimento, os dados mostram que a sala de recursos atendia 27 alunos, de $2^{\mathrm{a}}$ e $4^{\mathrm{a}}$ séries, dos quais apenas 13 estavam regularmente matriculados. Em relação às condições físicas da sala, pôdese observar que esta dispunha de materiais, carteiras, cadeiras e espaço adequados às atividades dos alunos, porém, o fato de estar ao lado do pátio resultava em interrupção das atividades, durante os períodos de intervalo dos alunos de outras turmas.

Os resultados referentes à análise do plano de ensino proposto para a sala de recursos mostram que, para todos os alunos, a proposta pedagógica era a mesma no que tange aos objetivos, conteúdos e estratégias de ensino. Mais especificamente, o objetivo educacional estava descrito como "minimizar as dificuldades de aprendizagem e alfabetizar os alunos com conteúdos defasados"; o conteúdo, como "leitura, escrita, interpretação e produção de textos", no que se referia à Língua Portuguesa e as estratégias educacionais, como o "trabalho por meio de uso de recursos ludopedagógicos". Embora todos os alunos matriculados no serviço possuíssem documentos individuais, não havia diferença na maneira como eles estavam preenchidos, ou seja, foi constatada a ausência de ajustes curriculares na proposta pedagógica.
Assim, pode-se questionar em que medida esta assume o papel de suporte ao ensino inclusivo, uma vez que, ao adotar uma mesma proposta pedagógica para todos os alunos, deixa de atender às especificidades de cada um deles no aprender, atuando, portanto, de maneira contrária ao indicado nas Diretrizes Nacionais (Ministério da Educação, 2001).

Quanto às características gerais da atuação pedagógica, pode-se destacar que esta tinha como foco as áreas de leitura e escrita, pelo fato de que a dificuldade maior dos alunos atendidos, sobretudo os da $4^{\mathrm{a}}$ série, concentrava-se na apropriação de conteúdos referentes à mesma. A decisão por direcionar a proposta a ser trabalhada pela professora da sala de recursos para essa área acadêmica foi tomada pela equipe escolar - direção, coordenação, professora especialista e professoras da sala comum.

Esse fato mostra uma tendência, neste serviço, a realizar um tipo de trabalho desvinculado do que propõe a Resolução SE No. 8 (2006), uma vez que a atuação pedagógica se restringe à alfabetização, se aproximando muito mais da ideia de reforço escolar, do que de uma proposta de ensino direcionada ao alcance de objetivos curriculares gerais.

Outro ponto a ser sinalizado refere-se à forma de encaminhamento de alunos para o serviço. Para cada aluno matriculado, era elaborado um laudo pela professora, com a anuência da equipe pedagógica, no qual havia menção à deficiência mental, expressão presente no próprio documento, como hipótese diagnóstica. Destaca-se, nesse caso, a falta de preparo da professora, como pedagoga, para aventar tais hipóteses, o que pode permitir a rotulação dos alunos sob a denominação de deficiência mental.

Como afirma Patto (1990), o fenômeno de fracasso escolar muitas vezes incorpora o discurso de cientificidade para explicar e justificar as dificuldades escolares, estabelecendo uma relação de causa e efeito entre estas e os déficits do aluno, desconsiderando, consequentemente, as diferentes práticas e relações que produziram esse processo.

De uma maneira geral, os resultados indicam que há uma nítida descaracterização da sala de recursos como um suporte do ensino inclusivo com locus na Educação Especial e cuja função é garantir o atendimento complementar ou suplementar aos alunos que dela necessitam para acessar o currículo comum.

Porém, pode-se dizer que, na sala de recursos investigada, alguns aspectos formais da inclusão educacional previstos na Resolução SE No. 8 (2006) foram adotados, tais como: (a) avaliação da aprendizagem conduzida por uma equipe escolar; (b) participação da família nesse processo, pois a proposta pedagógica a ser realizada com os alunos é discutida com os pais em reuniões com a professora especialista; (c) atendimento com carga horária equivalente a duas horas/aula e disponibilizado para qualquer série ou etapa do ensino fundamental. Ou seja, embora nesse serviço se cumpram algumas determinações legais, a efetivação deste como suporte no contexto de ensino inclusivo é questionável. 


\section{Análise das entrevistas}

A aplicação do roteiro norteador de entrevista ocorreu, em momentos anteriores e logo em seguida à proposta de intervenção, e teve como objetivo averiguar o conhecimento da professora especialista a respeito do funcionamento da sala de recursos. Para análise das entrevistas, foram considerados os seguintes itens: (a) função da sala de recursos; (b) definição de professor de sala de recursos; (c) concepção de necessidades educacionais especiais; (d) concepção de educação inclusiva; (e) atuação pedagógica; (f) trabalho com a família.

Pode-se perceber que, na entrevista realizada pós-intervenção, a professora muda a definição da sala de recursos, identificando-a como um apoio ao processo de aprendizagem, diferentemente do seu relato na primeira entrevista "sala de recursos é um suporte para o aluno que tem uma deficiência, uma defasagem, tanto na parte pedagógica quanto na parte psicológica", deixando de dar ênfase à especificidade pedagógica.

Essa ideia remete ao que se tinha no Paradigma dos Serviços (Aranha, 2001), no qual havia a crença de que pessoas com deficiência necessitavam de cuidados para se habilitar ou se reabilitar nas mais diversas instâncias e assim se tornar "iguais" aos outros tidos como "normais", portanto, ajustados social e emocionalmente.

Ao definir a sua função, a professora expõe nas duas entrevistas que seu papel é dar suporte profissional e humano aos alunos, gestores e professores do ensino comum no que se refere ao processo educacional. Como propõem alguns autores (Mazzeu, 1998; Neira, 2006), a prática pedagógica deve estar vinculada ao saber do professor como um indivíduo crítico e autônomo. Assim, dado o relato aparentemente vago da professora a respeito do suporte prestado, vale questionar que subsídios ela possui na sua realidade para exercer uma atuação dessa natureza.

Quanto à concepção de necessidades educacionais especiais, a professora as define, em ambas as entrevistas, como defasagens que devem ser identificadas, avaliadas e acompanhadas por profissionais especializados. De maneira contrária ao que propõem as Diretrizes Nacionais (Ministério da Educação, 2001) sobre o conceito de NEEs, o relato da docente remete à noção de deficiência dada no Paradigma dos Serviços, em que o foco de atenção era o indivíduo, cuja deficiência deveria ser objeto de intervenção de especialistas.

Em relação à concepção de educação inclusiva, a professora, na entrevista inicial, entende esse processo como o movimento de inserir alunos nas escolas regulares, para que estes desenvolvam habilidades de socialização e, já na entrevista posterior, ela acrescentou que há muito trabalho a ser feito, pois existem resistências em relação a esse movimento. A falta de suporte mencionada pela professora também é confirmada por autores como Berger (1995), Glória (2002), Góes e Laplane (2004) e Pietro (2003), a respeito de que falta muito para que as escolas se tornem inclusivas, em virtude de estas ainda estarem alicerçadas em um modelo tradicional.

Ao falar das características e dificuldades quanto à atuação pedagógica, a professora relata que recebe auxílio de uma equipe pedagógica, no entanto, durante a reaplicação do roteiro norteador, ela expõe a dificuldade de se estabelecer um trabalho junto ao professor da sala regular.

Dados de conversas informais com a professora, no entanto, revelaram que a equipe pedagógica da escola delega ao professor especialista boa parte da responsabilidade pelo processo educacional de alunos com NEEs, o que mostra uma realidade oposta ao que é estabelecido pelas Diretrizes Nacionais, na medida em que se propõe que as escolas mobilizem-se para construir um espaço que atenda a todos.

Por último, no que diz respeito ao trabalho com a família, a professora diz considerar importante a participação da família junto à escola, porém afirma que alguns pais, dependendo das dificuldades que seus filhos apresentam, são relutantes quanto a colocá-los na sala de recursos. Assim, percebe-se, na realidade investigada, um distanciamento da relação pais-escola da perspectiva de ensino inclusivo, a qual é dada pelas Diretrizes Nacionais como a construção de uma rede de apoio em que a família participa efetivamente do processo educacional de seus filhos.

Numa alusão geral aos dados encontrados, pode-se dizer que não houve mudanças substanciais no relato da professora durante a reaplicação do roteiro norteador, após o período de intervenção, exceto para os itens correspondentes à noção de ensino inclusivo e atuação pedagógica. Nesse caso, vale pensar em que medida os requisitos propostos pelos documentos legais (Resolução SE No. 8, 2006) têm fornecido respaldo teórico-metodológico para que o professor implemente ações educacionais inclusivas na realização de seu trabalho pedagógico.

\section{Análise da proposta de intervenção}

Em um primeiro momento, pode-se destacar que, para os três grupos - G1, G2 e G3 - a Língua Portuguesa, com foco em alfabetização, mostrou-se como área curricular de dificuldade comum a todos os alunos, porém ressalta-se aqui se não seria o caso de a escola prover atendimento educacional específico para atender a essa demanda. Uma vez que o trabalho de alfabetização poderia ocorrer na sala comum, esses dados confirmam que a sala de recursos no contexto investigado parece não estar adequada às funções previstas legalmente (Ministério da Educação, 2001).

Discute-se, nesse caso, o motivo pelo qual alunos com dificuldades em habilidades iniciais de leitura e escrita estariam sendo atendidos na sala de recursos, ou seja, em um serviço especializado, destinado ao atendimento a alunos com necessidades educacionais especiais. Como sugere Kassar (2004), fatos como esse evidenciam que, em uma escola de qualidade, as crianças que atualmente são atendidas sob o rótulo de inclusão teriam pleno êxito. Pode-se dizer que, na 
realidade investigada, a função da sala de recursos parece ter sido alterada como uma forma de suprir aparentes déficits no ensino ofertado nas salas regulares.

Quanto ao preenchimento dos itens das adaptações referentes a "Histórico de Aprendizagem e Desenvolvimento do Aluno", as descrições pautaram-se nos déficits e dificuldades apresentados pelos alunos, como "problemas de lateralidade, direcionamento, orientação”. A partir disso, pode-se dizer que o foco das respostas se remeteu à noção de sujeito menos capaz, ou seja, como aquele que estaria em uma condição de incapacidade em relação aos demais indivíduos tidos como normais, necessitando de atendimentos extraescolares para se desenvolverem academicamente (Aranha, 1991).

O item "Estilo e Motivação para a Aprendizagem" consistiu em um dos primeiros aspectos nos quais foi possível identificar algumas mudanças para os grupos G2 e G3, mostrando que a professora passou a identificar habilidades e interações dos alunos, como no trecho: "A aluna tem habilidade em reconhecer letras e ler palavras simples" ou "O aluno respeita os adultos e gosta de interagir com os colegas".

Como ressalta Mantoan (2001), assumir novos posicionamentos diante do processo de ensino e aprendizagem é um dos pontos fundamentais na implementação de ações educacionais inclusivas. Isto é, embora a intervenção tenha sido em parte satisfatória, para que a professora adotasse práticas responsivas às necessidades dos alunos, ainda assim, possibilitou um novo olhar para as relações de ensino e aprendizagem.

No que se refere aos itens correspondentes a objetivos, conteúdos propostos e estratégias didático-pedagógicas, os documentos foram preenchidos de maneira muito semelhante para os três grupos - G1, G2 e G3. Em relação aos objetivos nas adaptações curriculares, foram propostos o ler e o escrever, dentre outros. Quanto aos conteúdos, estavam previstas práticas de escrita, de leitura e de produção de textos. Finalmente, os procedimentos correspondiam, respectivamente, à leitura de textos, à cópia, ao ditado e à escrita, com o auxílio de recursos ludopedagógicos.

De modo geral, a realização das adaptações curriculares deu oportunidade para que a professora começasse a estabelecer relações entre os aspectos pedagógicos presentes no documento, tais como objetivos de ensino, estratégias de ensino e metodologia, e as práticas adotadas em sala de aula. Nesse ponto, cabe destacar a necessidade de se rever quais condições têm sido dadas no interior da escola a essa professora, para que ela exerça uma prática reflexiva, definida por Mazzeu (1998) como a busca, no saber docente, por uma mudança de postura, em relação aos processos de ensino e aprendizagem, que favoreça o desenvolvimento do professor e o desenvolvimento dos alunos.

Quanto à descrição do que o aluno consegue fazer com e sem ajuda em relação aos objetivos de ensino, por sua vez, pode-se dizer que o preenchimento do documento de adaptações curriculares possibilitou que a professora começasse a identificar atividades realizadas pelos alunos com e sem auxílio. Para o grupo G1, as descrições estiveram relacionadas aos déficits dos alunos, como no exemplo, "espera resposta correta e tem vocabulário com trocas"; porém, para os grupos G2 e G3, foram mencionadas atividades acadêmicas já dominadas pelo aluno, bem como as que ele realizava com ajuda, como no trecho: "consegue ler palavras complexas e interpretar textos com o auxílio da professora".

Dessa forma, pode-se dizer que a intervenção ajudou a professora a olhar para e a identificar, mesmo que superficialmente, as zonas de desenvolvimento real e proximal, definidas por Vygotsky (2001), respectivamente, como aquilo que a criança realiza de maneira autônoma e aquilo que ela faz com a ajuda de um parceiro mais capaz.

Por último, tem-se o item referente à avaliação. No que se refere à proposta de avaliação descrita nas adaptações curriculares, para os três grupos (G1, G2 e G3), a professora elencou dois procedimentos: (a) correção da tarefa até que a criança a realizasse corretamente; (b) sondagem que consistia na realização periódica de uma atividade de ditado, para verificar possíveis avanços na escrita. Embora durante a intervenção a professora tivesse sido solicitada a pensar em formas de avaliação para cada objetivo/conteúdo proposto, as avaliações não corresponderam aos objetivos e conteúdos de ensino trabalhados, reproduzindo a mesma tendência de avaliação apresentada no plano da sala de recursos.

Isso demonstra que a dificuldade em se pensar no processo de avaliação, no preenchimento das adaptações curriculares, pode ter sido resultado de certa indefinição a respeito do que se espera de cada aluno, ao longo do processo de aprendizagem. Ao contrário do que se constatou nessa realidade, uma proposta de avaliação na perspectiva de ensino inclusivo deve ter como foco o processo de aprendizagem e, consequentemente, a análise das condições para que isso ocorra (Ministério da Educação, 2001).

Em suma, pode-se dizer que, embora o preenchimento das adaptações tenha sido acompanhado pela pesquisadora, essa estratégia foi parcialmente eficaz para que a professora atentasse para as necessidades de cada um dos alunos, uma vez que ela elaborou cada um dos documentos de forma bastante semelhante uns com os outros, apesar de orientação contrária.

Assim, a intervenção foi efetiva em promover um repensar da professora a respeito de sua atuação pedagógica na sala de recursos, pois alguns dos elementos encontrados no Documento Individual de Adaptações Curriculares (Poker \& Oliveira, 2006) não estavam previstos no plano de ensino da professora, tais como, áreas curriculares de dificuldade, estratégias didático-pedagógicas, histórico de desenvolvimento e aprendizagem do aluno, estilo e motivação para aprender e o que ele realiza com e sem ajuda.

\section{Considerações finais}

Este estudo teve como objetivo caracterizar o funcionamento de uma sala de recursos e auxiliar a professora 
especialista atuante nesse serviço a implementar ações educacionais inclusivas junto a alunos com necessidades educacionais especiais, utilizando como ferramenta adaptações curriculares individuais.

O conjunto de dados analisados - caracterização da sala de recursos, entrevistas e uma proposta de intervenção educacional - permite concordar com os achados de Mantoan (2001), a respeito de que existem inúmeras discrepâncias entre o que se estabelece em termos legais e a realidade escolar. Se, por um lado, no contexto investigado são cumpridos alguns aspectos formais da legislação, por outro, ficam questionamentos quanto ao fato de que essa sala de recursos se constitui como suporte ao ensino inclusivo.

Os resultados referentes à análise da realidade investigada mostram que, embora a escola em questão cumpra formalmente os requisitos legais estabelecidos para a construção da educação inclusiva, o papel da sala de recursos, as características do atendimento pedagógico ofertado nesta, bem como a população a que atende parecem divergir do estabelecido legalmente em função de possíveis déficits em relação ao ensino ofertado nas salas comuns.

$\mathrm{Da}$ análise dos dados das entrevistas, pode-se depreender que, muitas vezes, o professor especialista ainda tem dúvida a respeito de suas funções, sente dificuldades e, além disso, se vê sozinho na responsabilidade de conduzir o processo educacional do aluno com NEEs. Isso mostra que talvez requisitos estabelecidos legalmente para a atuação em sala de recursos - Habilitação ou Licenciatura Plena em Pedagogia, curso de especialização com o mínimo de 360 horas de duração (Resolução SE No. 8, 2006) e participação em cursos de formação continuada - não sejam suficientes por si só para permitir que a professora mostrasse uma atuação consoante com a educação inclusiva.

A partir dos resultados obtidos durante a intervenção, pode-se dizer que esta serviu para que a professora começasse a refletir sobre as práticas adotadas em sala. Fazendo um paralelo com os processos de ensino e de aprendizagem, pode-se sugerir que a intervenção ajudou a professora a olhar e identificar, mesmo que superficialmente, as zonas de desenvolvimento real e proximal, como definidas por Vygotsky (2001), respectivamente, como aquilo que a criança realiza de maneira autônoma e aquilo que ela faz com a ajuda de um parceiro mais capaz. Nesse sentido, o preenchimento das adaptações permitiu o pensar da professora a respeito do ensino como um processo colaborativo em que o professor auxilia o aluno a realizar as tarefas para que, em seguida, ele possa realizá-las de modo autônomo, possibilitando assim o seu desenvolvimento.

Em relação a estudos futuros, propõem-se pesquisas dessa natureza envolvendo não apenas o professor da sala de recursos, mas também a equipe pedagógica da escola, além do acompanhamento do aluno com NEEs na sala de ensino comum, a fim de identificar os diferentes tipos de ajustes realizados para atender às suas necessidades no acesso ao processo educacional. Por se tratar de um estudo de caso, este trabalho não permite generalização dos dados e, para tanto, outras pesquisas são necessárias para possivelmente atingir esse objetivo.

Para finalizar, cabe pensar que a inclusão educacional pressupõe um novo modelo de escola (Oliveira, 2006). Nesse cenário, esta se constitui como um espaço de transformação social e, sendo assim, compõe um movimento que deve ter por preceito a construção de uma escola humanizadora.

\section{Referências}

Aranha, M. S. F. (1991). A interação social e o desenvolvimento das relações interpessoais do deficiente em ambiente integrado. Tese de doutorado não-publicada, Universidade de São Paulo, São Paulo.

Aranha, M. S. F. (2001). Paradigmas da relação da sociedade com as pessoas com deficiência. Revista do Ministério Público do Trabalho, 11(21), 160-173.

Berger, S. (1995). Inclusion: A legal mandate, a educational dream. Updating School Board Policies, 26(4), 1-4. Recuperado em 02 maio 2007, de http://www.eric.ed.gov/ PDFS/ED386789.pdf

Claser, E. A. (2001). Projeto de educação inclusiva: Propostas para a educação na diversidade. Dissertação de mestrado não-publicada, Universidade Federal de Santa Catarina, Florianópolis.

Correia, L. M. (1999). Alunos com necessidades educativas especiais nas classes regulares. Porto, Portugal: Porto Editora.

Declaração de Salamanca. (1994). Conferência realizada em 10 de junho de 1994. Recuperado em 10 abril 2006, de http://portal.mec.gov.br/seesp/arquivos/pdf/salamanca. pdf

Glória, D. M. A. (2002). Direito à educação escolar: O discurso da inclusão x a prática da exclusão. Educar em Revista, (20), 209-222. Recuperado em 02 maio 2007, de http://ojs.c3sl.ufpr.br/ojs2/index.php/educar/article/ view/2107/1759

Góes, M. C. R., \& Laplane, A. L. F. (2004). Políticas e práticas de educação inclusiva. Campinas, SP: Autores Associados.

Kassar, M. C. M. (2004). Matrículas de crianças com necessidades educacionais especiais na rede de ensino regular: Do que e de quem se fala? In M. C. R. Góes \& A. L. F. Laplane (Orgs.), Políticas e práticas de educação inclusiva (pp. 49-68). Campinas, SP: Autores Associados.

Landívar, J. G., \& Hernández, R. S. (1995). Adaptaciones curriculares: Guia para los professores tutores de educación especial. Madrid: General Pardinas.

Leite, L. P. (2004). Educador especial: Reflexões e críticas sobre sua prática pedagógica. Revista Brasileira de Educação Especial, 10(2), 131-142. 
Mantoan, M. T. E. (Org.). (2001). Caminhos pedagógicos da inclusão: Como estamos implementando a educação (de qualidade) para todos nas escolas brasileiras. São Paulo: Memnon.

Mazzeu, F. J. C. (1998). Uma proposta metodológica para a formação continuada de professores na perspectiva histórico-social. Cadernos CEDES, 19(44), 59-72. Recuperado em 15 março 2006, de http://www.scielo.br/scielo.php?pid=S010132621998000100006\&script $=$ sci_arttext

Ministério da Educação. (2001). Diretrizes Nacionais para a Educação Especial na Educação Básica. Brasília, DF: MEC/SEESP. Recuperado em 13 março 2006, de http:// portal.mec.gov.br/seesp/arquivos/pdf/diretrizes.pdf

Neira, M. G. (2006). Representações sobre a docência em educação física: Modificações a partir de um programa de formação. Paidéia, 16(33), 101-110.

Oliveira, A. A. S. (2006). Inclusão no Brasil: Políticas públicas para o educando com necessidades educacionais especiais. In K. F. Genaro, D. A. C. Lamônica, \& M. C. Bevilacqua (Orgs.), O processo de comunicação: Contribuição para a formação de professores na inclusão de individuos com necessidades educacionais especiais (pp. 255-276). São José dos Campos, SP: Pulso.

Oliveira, A. A. S., \& Leite, L. P. (2002, 29 de outubro). O papel da educação especial no sistema educacional inclusivo. Jornal Diário de Marília, p. 12.

Patto, M. H. S. (1990). A produção do fracasso escolar: Histórias de submissão e rebeldia. São Paulo: T. A. Queiroz.

Pino, A. (2005). As marcas do humano: As origens da constituição cultural da criança na perspectiva de Lev Vigotski. São Paulo: Cortez.

Poker, R. B., \& Oliveira, A. A. S. (2006). Documento individual de adaptações curriculares. Marília, SP: Universidade Estadual Paulista.

Prieto, R. G. (2003). Políticas públicas de inclusão: Compromissos do poder público, da escola e dos professores. Revista de Educação, (16), 5-14. Recuperado em 09 outubro 2006, de http://saci.org.br/index. php? modulo $=$ akemi\&parametro $=9964$

Resolução SE No. 8, de 26 de janeiro de 2006. (2006, 26 de janeiro). Dispõe sobre a necessidade da oferta de condições, que agilizem o atendimento aos alunos da rede pública estadual com necessidades educacionais especiais. São Paulo: Secretaria da Educação. Recuperado em 09 outubro 2006, de http://siau.edunet.sp.gov.br

Resolução SE No. 11, de 31 de janeiro de 2008. (2008, 31 de janeiro). Dispõe sobre a fixação da sede de controle de frequência e de critérios relativos à apuração de faltas do pessoal docente. São Paulo: Secretaria da Educação. Recuperado em 20 junho 2009, de http://siau.edunet. sp.gov.br/ItemLise/arquivos/11_08.HTM
Stainback, S., \& Stainback, W. (1999). Inclusão: Um guia para educadores. Porto Alegre: Artes Médicas.

Vygotsky, L. S. (2001). A construção do pensamento e da linguagem. São Paulo: Martins Fontes.

Marileide Antunes de Oliveira é doutoranda do Programa de Pós-graduação em Psicologia da Universidade Federal de São Carlos.

Lúcia Pereira Leite é Professora Doutora do Departamento de Psicologia da Faculdade de Ciências da Universidade Estadual Paulista, campus Bauru-SP.

Recebido: 07/07/2009

$1^{a}$ revisão: $30 / 03 / 2010$

$2^{a}$ revisão: $03 / 11 / 2010$

Aceite final: 09/11/2010 